\title{
Incidence Differences Between First Primary Cancers and Second Primary Cancers Following Skin Squamous Cell Carcinoma as Etiological Clues
}

This article was published in the following Dove Press journal: Clinical Epidemiology

Guoqiao Zheng, (D) ${ }^{1-3}$ Kristina Sundquist, ${ }^{4-6}$ Jan Sundquist, (1D) Asta Försti, $\mathbb{D D}^{1,4,7,8}$ Akseli Hemminki, $\mathbb{D}^{9,10}$ Kari Hemminki ${ }^{1,2,4,11}$

'Division of Molecular Genetic Epidemiology, German Cancer Research Center (DKFZ), Heidelberg D-69120, Germany; ${ }^{2}$ Division of Cancer Epidemiology, German Cancer Research Center (DKFZ), Heidelberg D-69I20,

Germany; ${ }^{3}$ Faculty of Medicine, University of Heidelberg, Heidelberg, Germany; ${ }^{4}$ Center for Primary Health Care Research, Lund University, Malmö 205 02, Sweden;

${ }^{5}$ Department of Family Medicine and Community Health, Department of Population Health Science and Policy, Icahn School of Medicine at Mount Sinai, New York, NY, USA; ${ }^{6}$ Center for Community-Based Healthcare Research and Education (CoHRE), Department of Functional Pathology, School of Medicine, Shimane University, Izumo, Japan; ${ }^{7} \mathrm{Hopp}$ Children's Cancer Center (KiTZ), Heidelberg, Germany; ${ }^{8}$ Division of Pediatric Neurooncology, German Cancer Research Center (DKFZ), German Cancer Consortium (DKTK), Heidelberg, Germany; ${ }^{9}$ Cancer Gene Therapy Group, Translational Immunology Research Program, University of Helsinki, Helsinki, Finland; ${ }^{10}$ Comprehensive Cancer Center, Helsinki University Hospital, Helsinki, Finland; ' 'Faculty of Medicine and Biomedical Center in Pilsen, Charles University in Prague, Pilsen 30605, Czech Republic

Correspondence: Kari Hemminki Division of Cancer Epidemiology, German Cancer Research Center (DKFZ), Im

Neuenheimer Feld 580, Heidelberg

69120 , Germany

Tel +496221421800

$\mathrm{Fax}+496221421810$

Email kari.hemminki@dkfz.de
Background: Most literature on second primary cancers (SPCs) focuses on possible factors, which may increase the risk of these cancers, and little attention has been paid for the overall incidence differences between first primary cancers (FPCs) and same SPCs. We wanted to compare the incidence rates for all common cancers when these were diagnosed as FPCs and SPCs after invasive and in situ squamous cell carcinoma (SCC) of the skin, which are usually treated by surgery only.

Methods: Cancers were identified from the Swedish Cancer Registry from the years 1990 through to 2015, and they included, in addition to skin cancers, 20 male cancers totaling 484,850 patients and 22 female cancers totaling 452,909 patients. Standardized incidence rates and relative risks (RRs) were calculated for sex-specific common cancers as FPC and as SPC after skin SCC. Spearman rank correlations were used in the analysis of incidence ranking of FPC and SPC.

Results: Of total, 29,061 men and 23,533 women developed invasive SCC and 27,842 men and 36,383 women in situ SCC. The total number of 20 other male cancers was 484,850 and of 22 female cancers it was 452,909 . Rank correlations ranged from 0.90 to $0.96\left(\mathrm{P} \sim 5 \times 10^{-6}\right)$, indicating that overall skin SCC did not interfere with SPC formation. The exceptions were increased SPC risks for melanoma, sharing risk factors with skin SCC, and non-Hodgkin and Hodgkin lymphoma, and cancers of the upper aerodigestive tract, connective tissue, and male and female genitals suggesting contribution by skin cancer initiated immune dysfunction.

Conclusion: The incidence ranking of SPCs after skin cancers largely follows the incidence ranking of FPCs indicating that overall skin SCC does not greatly interfere with the intrinsic carcinogenic process. The main deviations in incidence between FPC and SPC appeared to be due to shared risk factors or immunological processes promoting immune responsive cancer types.

Keywords: skin cancer, second cancer, first primary cancer, immune disturbance

\section{Plain Language Summary}

In this study, we compared the incidence of first primary cancers and the incidence of the same cancers as second primary cancer after squamous cell skin cancer. Skin cancers are treated by surgery, which is not a risk for second cancer, but skin cancers show immunological disturbances that may increase the risk of immune responsive cancers. The results showed that the incidence ranking of second cancer followed closely the incidence ranking of these cancers as first cancer. The exceptions were cancers, such as non-Hodgkin lymphoma, the incidence of which was increased as second cancer probably due to shared risk factors, such as immunological disturbances. 


\section{Introduction}

Multiple primary cancers are known to be diagnosed in cancer patients and Vogt et al noted that as far back as 1921 a study reported that $4.5 \%$ of cancers appeared to be "of multiple growth". ${ }^{1}$ Multiple primary cancers are considered when two or more independent tumors are diagnosed in an individual, but the exact definitions differ internationally and nationally. ${ }^{1}$ Multiple primary cancers have been of large etiological and clinical interest. ${ }^{2,3}$ However, as the frequency of new primary cancers drastically decreases after the second primary cancer (SPC) much of the literature has focused on SPCs. As examples, in prostate cancer patients, SPCs account for $11.3 \%$ of first primary cancers (FPCs) and third primaries account for $10.5 \%$ of SPCs; in melanoma, the respective proportions are $13.3 \%$ and $17.4 \%$ (including multiple melanomas). ${ }^{4,5}$ In most studies, the incidence of SPC is compared to the incidence of that cancer as (FPC) and hence the calculated relative risks (RRs) are used as the outcome measure. In general, the studies report SPCs with an increased risk, for example, due to carcinogenic chemo-or radiotherapies. However, our recent studies on SPC after prostate cancer suggested that SPCs were "autonomous" from prostate cancer because the frequencies of SPC correlated with the frequencies of these cancers as FPC and the risk of SPC was increased by the familial history of that cancer, irrespective of prostate cancer. ${ }^{4,6}$ Moreover, the RRs for SPCs were equal in screening detected and other prostate cancer.

We want to address the question of whether the incidence of cancer X differs when it is FPC or SPC after cancer $\mathrm{Y}$, hypothesizing that a possible difference may reveal something about cancer etiology. For cancer $\mathrm{Y}$, we selected skin squamous cell carcinoma (SCC) because invasive and in situ forms are common thus allowing high statistical power. We thus assessed the incidence of cancer X as FPC and as SPC after skin SCC. In Sweden, invasive SCC ranks second among male and female cancers, and in situ SCC has become more common than invasive SCC. ${ }^{7}$ Furthermore, these cancers are usually treated by surgery and the patients are not subjected to potentially carcinogenic treatments. ${ }^{8}$ Common risk factors for SCC include cumulative exposures to ultraviolet (UV) radiation, viral infections, immune dysfunctions and sunsensitive skin. ${ }^{8-10}$ The role of immune dysfunction is illustrated by the high risk of SCC in immune-suppressed patients. ${ }^{11-13}$ We used data from the Swedish Cancer
Registry to systematically compare the incidence of FPC and SPC when SPC was recorded after invasive or in situ SCC; the 20 most common cancers were analyzed and their incidence ranking was tested by rank correlation. While our primary hypothesis was that the ranking remains uniform, the secondary hypothesis was to gain etiological clues about cancers that changed their ranking.

\section{Methods}

Data of cancer patients were obtained from the Swedish Cancer Registry, based on the international classification of diseases 7th revision (ICD-7) and later revisions. The Registry is population-based and covers practically all cancers diagnosed in Sweden. ${ }^{14,15}$ We identified all individuals who were diagnosed with invasive and in situ SCC with histological identifiers (WHO/HS/CANC/24.1 Histology Code, "PAD") 146 and 144, respectively. In addition, data on most common cancers were retrieved, including 20 male and 22 female cancers. Upper aerodigestive tract (UAT) included cancers in the mouth, lip, pharynx and larynx. We followed newly diagnosed in situ and invasive skin cancer patients for the diagnosis of any invasive SPC; the follow-up for skin cancers were started after 1990 from the date of diagnosis until diagnosis of SPC, emigration, death, or 31 December 2015, whichever occurred earliest. A sex-specific agestandardized (world standard population) incidence rate for cancer X as SPC was calculated. Similarly, a sexspecific and age-standardized incidence rate for cancer $\mathrm{X}$ as FPC was calculated. For comparison of incidence rates, RRs and the corresponding $95 \%$ confidence intervals (95\%CIs) were calculated for SPC using the population incidence of the same FPC as a reference and adjusting the rates for 5-year age group, 5 year-calendar period, socioeconomic status (6 groups) and place of residence (3 groups) in Poisson regression. Correlation of ranking for incidence rates between FPC and SPC was tested by Spearman's rank correlation rho. All statistical analyses were done with SAS version 9.4 and $\mathrm{R}$ version 3.4. All the tests were two-tailed and $\mathrm{P}$ value below 0.05 was regarded as statistically significant.

The study was approved by the Regional Ethical Review Board in Lund, February 6, 2013, without requirement for informed consent and was conducted in accordance with the tenets of the Declaration of Helsinki. People could opt out of the study, which was advertised in major newspapers, before the project datasets were constructed. This opting is common in Swedish publically 
collected databases but opting out is utterly rare. The project datasets are located at the Center for Primary Health Care Research in Malmö, Sweden.

\section{Results}

Among 16.1 million individuals who were followed from 1990 to diagnosis of SPC, emigration, death, or 31 December 2015, and 29,061 men and 23,533 women developed invasive SCC; 27,842 men and 36,383 women developed in situ SCC. The total number of 20 other male cancers was 484,850 and that of 22 female cancers was 452,909. Median (interquartile) age at diagnosis of invasive SCC was 78 (70-84) years for men and 80 (71-87) for women and that of in situ SCC was 82 (75-87) for men and 78 (69-84) for women. Median (interquartile) time from first invasive SCC to SPC was 2 (1-6) years for men and $2(1-6)$ for women, and for in situ SCC, it was $3(0-7)$ for men and $3(1-7)$ for women.

Table 1 shows incidence rates of FPC and SPC diagnosed after invasive SCC in men. The case numbers, incidence rates for FPC and SPC and the related ranks are listed in columns 2 to 7, followed by adjusted RR for SPC compared to FPC. Among ranking, upper aerodigestive cancer (UAT) climbed from position 11 to position 5 as SPC. RR for UAT after skin SCC compared to UAT as an FPC was also the highest (3.79), followed by melanoma (3.23). Other cancers with RRs over 2.0 were connective tissue (2.64) and breast (2.62) cancers and non-Hodgkin lymphoma (NHL 2.37); the RRs over 2.0 were bolded. RRs for all other cancers were also significantly increased (95\% CIs did not include 1.00), except for myeloma and Hodgkin lymphoma and for endocrine and thyroid cancers. The overall RR was 1.47 .

The rates of common cancers in women as FPC and SPC are shown in Table 2 when SPCs were diagnosed after invasive SCC. Among ranking, melanoma, NHL and UAT climbed from positions 4,10 and 17 as FPCs to respective positions 2, 6 and 8 as SPCs. RRs for these cancers exceeded 2.0 (2.61, 2.09 and 3.68, respectively). The RR for Hodgkin lymphoma was 2.20 (0.98-4.93). RRs for breast, colorectal, lung, endometrial, ovarian, bladder, female genital and connective tissue cancers and

Table I Incidence of Common Cancers as First Primary Cancer and Second Primary Cancer, and Respective Relative Risk (RR) in Men

\begin{tabular}{|c|c|c|c|c|c|c|c|c|c|}
\hline \multicolumn{4}{|c|}{ First Primary Cancer } & \multicolumn{6}{|c|}{ Second Primary Cancer After Invasive SCC } \\
\hline \multirow{2}{*}{$\begin{array}{l}\text { Cancer } \\
\text { Prostate }\end{array}$} & \multirow{2}{*}{$\begin{array}{l}\begin{array}{l}\text { Number of } \\
\text { Cases }\end{array} \\
|85,08|\end{array}$} & \multirow{2}{*}{$\begin{array}{l}\text { Standardized Rate } \\
\text { I/100,000 } \\
95.2\end{array}$} & \multirow{2}{*}{$\begin{array}{l}\text { Rank I } \\
\text { I }\end{array}$} & \multirow{2}{*}{$\begin{array}{l}\begin{array}{l}\text { Number of } \\
\text { Cases }\end{array} \\
1483\end{array}$} & \multirow{2}{*}{$\begin{array}{l}\text { Standardized Rate } \\
2 / 100,000 \\
110.4\end{array}$} & \multirow{2}{*}{$\begin{array}{l}\text { Rank2 } \\
\text { I }\end{array}$} & \multirow{2}{*}{$\begin{array}{l}\mathbf{R R} \\
1.16\end{array}$} & \multicolumn{2}{|c|}{$95 \% \mathrm{Cl}$} \\
\hline & & & & & & & & 1.10 & 1.22 \\
\hline Colorectum & 60,037 & 32.2 & 2 & 545 & 42.5 & 3 & 1.32 & 1.21 & 1.44 \\
\hline Lung & 41,165 & 23.5 & 3 & 372 & 40.9 & 4 & 1.74 & 1.57 & 1.93 \\
\hline Bladder & 35,818 & 18.9 & 4 & 374 & 26.5 & 7 & 1.40 & 1.27 & 1.55 \\
\hline Melanoma & 22,812 & 14.7 & 5 & 355 & 47.5 & 2 & 3.23 & 2.91 & 3.60 \\
\hline Leukemia & 17,318 & 11.3 & 6 & 180 & 21.7 & 8 & 1.92 & 1.66 & 2.23 \\
\hline $\mathrm{NHL}$ & $|8,4| 4$ & 11.3 & 7 & 237 & 26.8 & 6 & 2.37 & 2.08 & 2.70 \\
\hline Nervous system & 14,199 & II.I & 8 & 45 & 15.0 & 9 & 1.35 & 1.01 & 1.81 \\
\hline Kidney & 13,922 & 8.7 & 9 & 98 & 13.3 & 10 & 1.53 & 1.26 & 1.87 \\
\hline Stomach & 13,800 & 7.3 & 10 & 152 & 12.4 & 11 & 1.70 & 1.44 & 1.99 \\
\hline UAT & $|I, 37|$ & 7.2 & 11 & 195 & 27.3 & 5 & 3.79 & 3.29 & 4.38 \\
\hline Liver & 10,990 & 6.3 & 12 & 82 & 8.8 & 12 & 1.39 & 1.12 & 1.72 \\
\hline Myeloma & 7202 & 4.0 & 13 & 52 & 4.6 & 14 & 1.15 & 0.88 & 1.51 \\
\hline Endocrine & 5558 & 3.9 & 14 & 16 & 3.9 & 15 & 0.99 & 0.60 & 1.62 \\
\hline Connective tissue & 3564 & 2.4 & 15 & 46 & 6.3 & 13 & 2.64 & 1.97 & 3.54 \\
\hline Hodgkin lymphoma & 2399 & 2.0 & 16 & 8 & 3.8 & 16 & 1.91 & 0.95 & 3.85 \\
\hline Thyroid & 2213 & 1.6 & 17 & 10 & 2.3 & 18 & 1.45 & 0.78 & 2.71 \\
\hline Small intestine & 2423 & 1.5 & 18 & 21 & 2.5 & 17 & 1.65 & 1.07 & 2.54 \\
\hline Male genital & 1835 & I.I & 19 & 22 & 2.1 & 19 & 1.94 & 1.27 & 2.96 \\
\hline Breast & 803 & 0.5 & 20 & 14 & 1.3 & 20 & 2.62 & 1.54 & 4.47 \\
\hline All* & 515,982 & 256.0 & - & 4662 & 376.3 & - & $\mathrm{I} .47$ & 1.43 & 1.51 \\
\hline
\end{tabular}

Notes: *Skin cancer is removed from all cancers; some rare cancers, not listed in Table I are included. Bolding shows RRs $>2.00$.

Abbreviations: SCC, squamous cell carcinoma; NHL, non-Hodgkin lymphoma; UAT, upper aerodigestive tract. 
Table 2 Incidence of Common Cancers as First Primary Cancer and Second Primary Cancer, and Respective Relative Risk (RR) in Women

\begin{tabular}{|c|c|c|c|c|c|c|c|c|c|}
\hline \multicolumn{4}{|c|}{ First Primary Cancer } & \multicolumn{6}{|c|}{ Second Primary Cancer After Invasive SCC } \\
\hline \multirow{2}{*}{$\begin{array}{l}\text { Cancer } \\
\text { Breast }\end{array}$} & \multirow{2}{*}{$\begin{array}{l}\text { Number of } \\
\text { Cases }\end{array}$} & \multirow{2}{*}{$\begin{array}{l}\text { Standardized Rate } \\
1 / 100,000 \\
83.6\end{array}$} & \multirow{2}{*}{$\begin{array}{l}\text { Rank I } \\
I\end{array}$} & \multirow{2}{*}{$\begin{array}{l}\begin{array}{l}\text { Number of } \\
\text { Cases }\end{array} \\
529\end{array}$} & \multirow{2}{*}{$\begin{array}{l}\text { Standardized Rate } \\
2 / 100,000 \\
103.7\end{array}$} & \multirow{2}{*}{$\begin{array}{l}\text { Rank2 } \\
\text { I }\end{array}$} & \multirow{2}{*}{$\begin{array}{l}\mathbf{R R} \\
1.24\end{array}$} & \multicolumn{2}{|c|}{$95 \% \mathrm{Cl}$} \\
\hline & & & & & & & & 1.14 & 1.35 \\
\hline Colorectum & 56,198 & 24 & 2 & 354 & 30.0 & 3 & 1.25 & 1.13 & 1.39 \\
\hline Lung & 31,306 & 16.4 & 3 & 136 & 22.1 & 4 & 1.35 & 1.14 & 1.60 \\
\hline Melanoma & 23,800 & 15.2 & 4 & $|8|$ & 39.7 & 2 & 2.61 & 2.25 & 3.02 \\
\hline Endometrium & 28,548 & 14.7 & 5 & 134 & 19.0 & 5 & 1.29 & 1.09 & 1.53 \\
\hline Nervous system & 16,042 & 11.5 & 6 & 19 & 7.5 & 10 & 0.65 & 0.41 & 1.02 \\
\hline Ovary & 18,523 & 11 & 7 & 68 & 15.4 & 7 & 1.40 & 1.10 & 1.77 \\
\hline Leukemia & 13,833 & 7.9 & 8 & 95 & 13.4 & 9 & 1.69 & 1.38 & 2.07 \\
\hline Cervix & 11,053 & 7.7 & 9 & 19 & 7.4 & II & 0.96 & $0.6 \mathrm{I}$ & $\mid .51$ \\
\hline $\mathrm{NHL}$ & 15,152 & 7.6 & 10 & 132 & 15.9 & 6 & 2.09 & 1.76 & 2.48 \\
\hline Endocrine & 11,393 & 7.2 & 11 & 20 & 5.5 & 14 & 0.77 & 0.49 & 1.19 \\
\hline Bladder & 12,134 & 5.2 & 12 & 83 & 6.9 & 12 & 1.33 & 1.07 & 1.65 \\
\hline Kidney & 9520 & 5 & 13 & 32 & 5.0 & 15 & 0.99 & 0.70 & 1.40 \\
\hline Liver & 10,939 & 4.8 & 14 & 52 & 5.7 & 13 & 1.18 & 0.90 & 1.55 \\
\hline Thyroid & 5758 & 4.1 & 15 & 9 & 3.3 & 19 & 0.81 & 0.42 & 1.57 \\
\hline Stomach & 8889 & 3.7 & 16 & 50 & 4.5 & 16 & 1.22 & 0.92 & 1.61 \\
\hline UAT & 6932 & 3.7 & 17 & 105 & 13.6 & 8 & 3.68 & 3.03 & 4.47 \\
\hline Myeloma & 5898 & 2.6 & 18 & 27 & 2.6 & 21 & 1.00 & 0.69 & 1.47 \\
\hline Female genital & 4450 & 1.9 & 19 & 44 & 3.5 & 18 & 1.86 & 1.38 & 2.51 \\
\hline Connective tissue & 2903 & 1.8 & 20 & 17 & 3.2 & 20 & 1.76 & 1.09 & 2.84 \\
\hline Hodgkin lymphoma & 1934 & 1.7 & 21 & 6 & 3.7 & 17 & 2.20 & 0.98 & 4.93 \\
\hline Small intestine & 2112 & I & 22 & 7 & 0.8 & 22 & 0.83 & 0.39 & 1.74 \\
\hline All* & 481,702 & 237.7 & - & 2371 & 325.6 & - & 1.37 & 1.32 & 1.43 \\
\hline
\end{tabular}

Notes: *Skin cancer is removed from all cancers; some rare cancers, not listed in Table 2 are included. Bolding shows RRs $>2.00$.

Abbreviations: SCC, squamous cell carcinoma; NHL, non-Hodgkin lymphoma; UAT, upper aerodigestive tract.

leukemia were also significant. RRs for six cancers were below 1.00 but none of these were significant. The overall RR was 1.37 .

The rates after in situ SCC in men are shown in Supplementary Table 1 . All RRs that were over 2.0 in Table 1 were over 2.0 in Supplementary Table 1, although some RRs after in situ SCC were somewhat smaller. RRs for leukemia (2.13) and Hodgkin lymphoma (2.57) were somewhat higher and for male genital cancer (1.93) the RR was equal compared to the results in Table 1. The only difference to Table 1 was for male breast cancer, the RR of which was much lower, 1.15 (yet 95\% CIs overlapped). The overall RR was 1.40 .

Female rates after in situ SCC are shown in Supplementary Table 2. The results were consistent with data in Table 2: however, the RR of 3.36 for melanoma was significantly higher than the RR of 2.61 for melanoma in Table 2. The overall RR was 1.35 .

In Table 3 we show results from incidence-ranking analysis conducted for SPCs following invasive and
Table 3 Spearman Rank Correlation Between Incidences of the First Primary Cancer and Second Primary Cancer After Invasive and in situ SCC

\begin{tabular}{|l|l|l|l|}
\hline Gender & SCC & $\begin{array}{l}\text { Spearman Rank Correlation } \\
\text { Coefficient (r) }\end{array}$ & $\mathbf{P}$ \\
\hline Invasive & Men & 0.95 & $5.95 \times 10^{-6}$ \\
& Women & 0.90 & $3.45 \times 10^{-6}$ \\
\hline In situ & Men & 0.96 & $6.41 \times 10^{-6}$ \\
& Women & 0.94 & $4.03 \times 10^{-6}$ \\
\hline
\end{tabular}

Abbreviation: SCC, squamous cell carcinoma.

in situ SCC in men and women, summarizing the results from the above tables. Rank correlations were marginally higher for men than for women and higher after in situ than after invasive SCC, all correlations were highly significant $\left(\mathrm{P} \sim 5 \times 10^{-6}\right)$.

The results for male RRs are summarized in Figure 1 illustrating the systematic covariation of RRs for cancers when diagnosed after invasive and in situ SCC. UAT after 


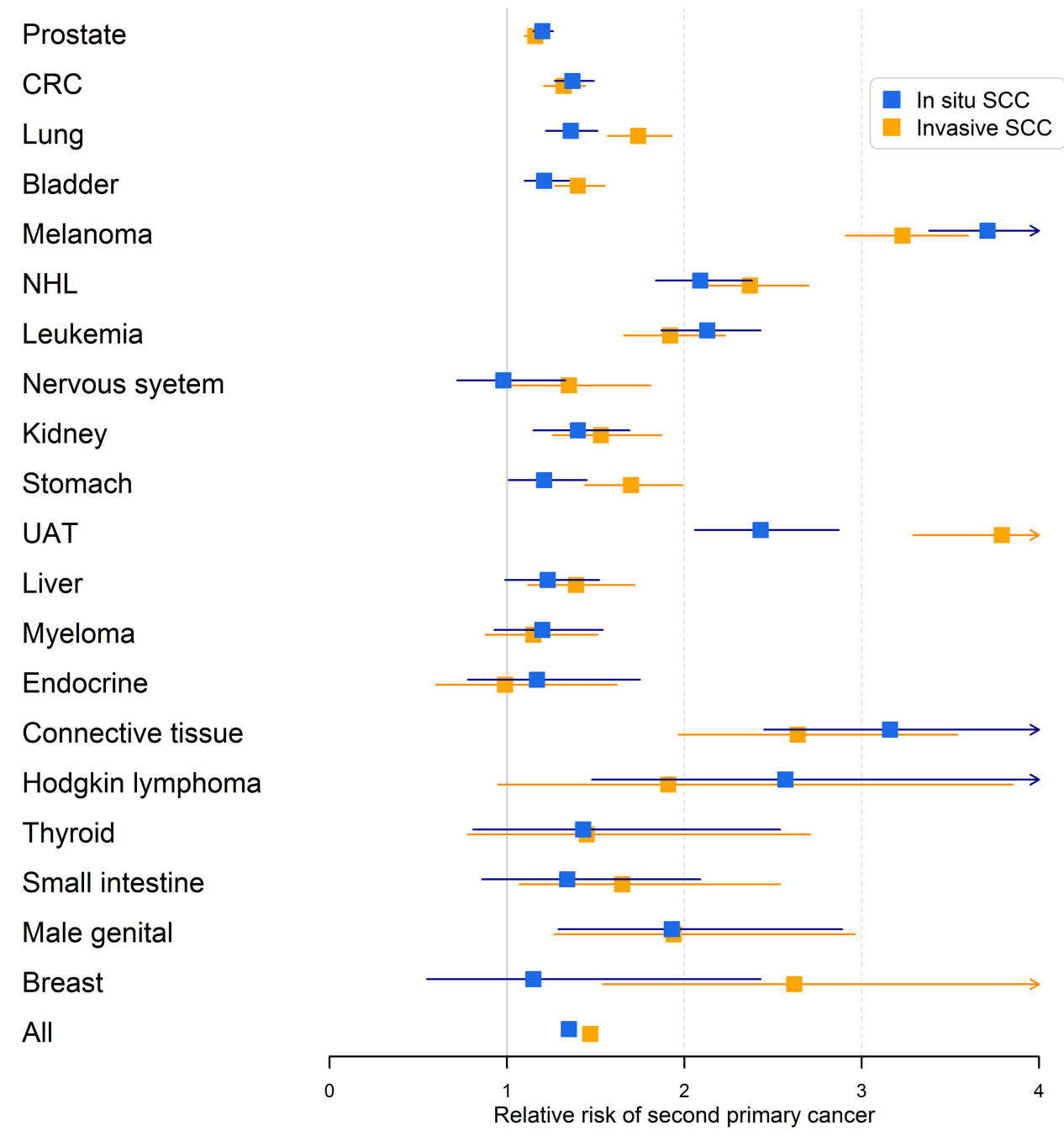

Figure I Relative risks (RRs) for second primary cancer in men after invasive and in situ SCC of the skin. The error bars show $95 \%$ confidence intervals.

invasive SCC wass a real deviation with highest of all RRs and the largest difference when diagnosed after invasive and in situ SCC. Similarly, female data are shown in Figure 2 confirming the covariation of invasive and in situ results and the high risk of UAT, especially after invasive SCC.

\section{Discussion}

A novel set of findings was revealed by comparing the incidence ranking of SPCs appearing after skin SCC to the ranking of same cancers as FPCs. The ranking of FPC was largely maintained among SPCs in men and women, with rank correlations at or above 0.90 and highly significant P-values. SPCs following in situ SCC showed marginally higher correlation than SPCs after invasive SCC, and male correlations were marginally higher than female correlations. The high correlations suggest that skin cancer does not influence the formation of SPCs and thus SPCs appear to be autonomous from skin cancer which seems to resemble SPCs after prostate cancer. ${ }^{4,6}$ The higher correlations after in situ than invasive SCC may be rationalized by in situ being a precursor stage of shorter life-span and size than invasive lesions. ${ }^{8}$

If ranking was identical for FPC and SPC the correlation would be 1.00 . A perfect ranking would be maintained if the incidence of all cancers remained stable or if systematically increased or decreased for all cancers. The overall RRs were 1.47 (men) and 1.37 (women) after invasive SCC and 1.40/1.35 after in situ SCC indicating that incidence levels were generally increased for SPCs compared to FPCs. The deviation from rho $=1.00$ indicates deviations in ranking and thus positive or negative interference of the underlying carcinogenic process that drives cancer incidence. For individual cancers, 


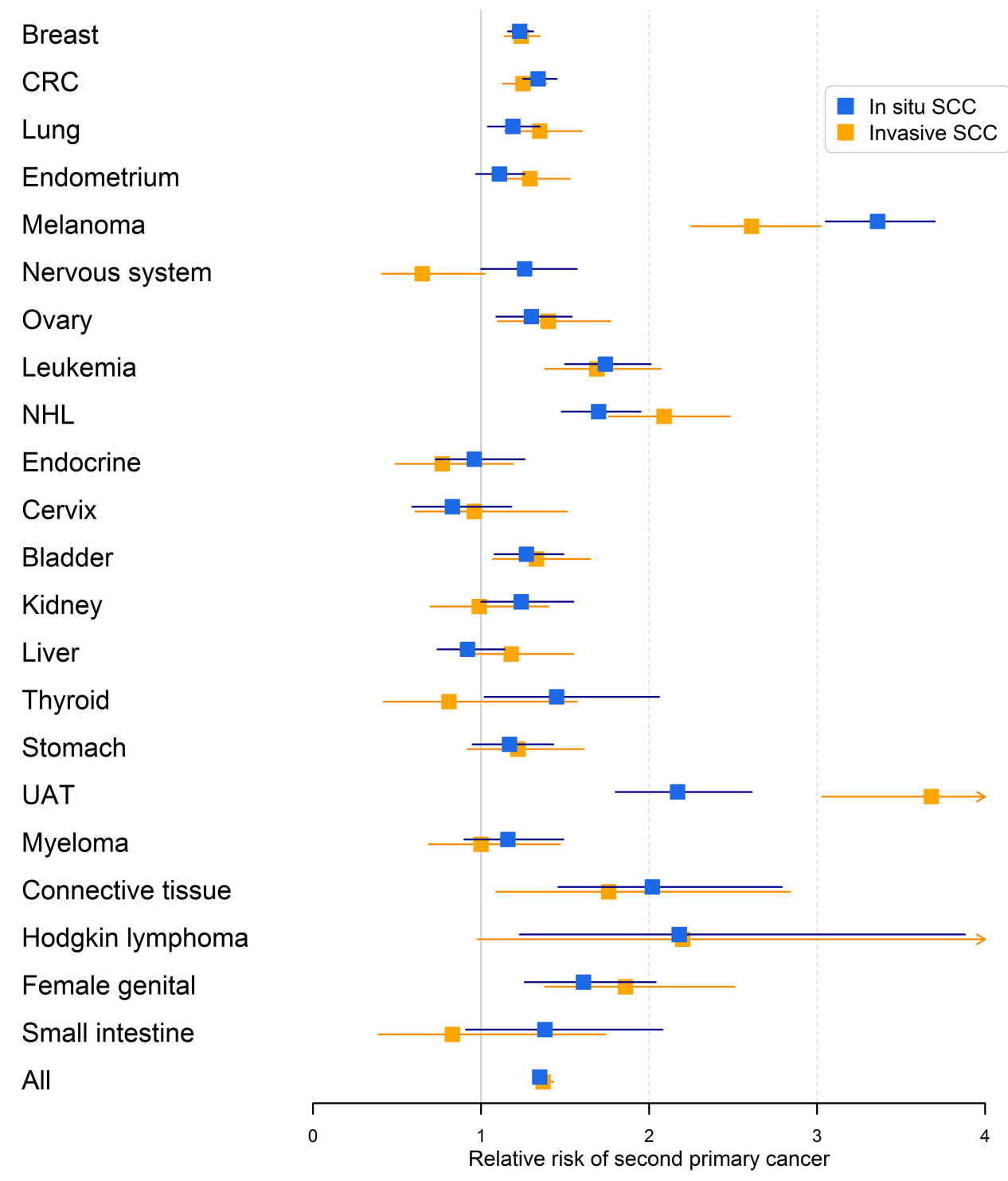

Figure 2 Relative risks (RRs) for second primary cancer in women after invasive and in situ SCC of the skin. The error bars show $95 \%$ confidence intervals.

a positive interference would be shown by an $R R>1.00$ and a negative one by an $\mathrm{RR}<1.00$. We found no indication of negative interference as no single RR was significantly below 1.00 . This is also technically reassuring because a deficit in reporting of SPCs would also contribute to low $\mathrm{RR} ;{ }^{16,17}$ this concurs with data reporting a generally high coverage of cancers by the Swedish Cancer Registry. ${ }^{14}$

Possible causes or contributing factors for SPCs are many, but probably the most important ones are intensive medical surveillance after the diagnosis of FPC, therapy for FPC, shared genetic or non-genetic risk factors between FPC and SPC and immune dysfunction elicited by FPC. ${ }^{2,18,19}$ In the case of skin cancer therapy is not an issue, but medical surveillance probably is, because SPCs were diagnosed relatively shortly after skin cancers (2-3 years) which are generally diagnosed in elderly subjects (median diagnostic ages were 78-82 years in this study). ${ }^{20}$ However, as practically all cancers reported to the Swedish Cancer Registry are histologically confirmed, the effect of medical surveillance would be antedating of diagnoses rather than introducing wrong diagnoses.

There was ample evidence for non-random positive interference, which marked a set of particular cancers. The RRs between incidence rates showed some systematic changes, replicated between sexes and invasive and in situ forms, which can be visualized in Figures 1 and 2. Such consistent changes should offer some etiological clues. 
The increased RRs for melanoma are likely a consequence of shared risk factors (solar radiation and sensitive skin type). Melanoma is an immune responsive tumor, as shown by successes in treatment with checkpoint blocking agents, and immune mechanisms may also contribute to melanoma development. ${ }^{21}$ The increased RRs for NHL and Hodgkin lymphoma, and cancers of the UAT, connective tissue and male and female genitals may be explained by immune dysfunction caused by skin SCC or a shared host risk factor. These cancers are known to be related to iatrogenic immune suppression for organ transplantation. ${ }^{11,12,22-24}$ UAT and genital cancer are related to human papilloma virus (HPV) infections, which are known to be intensified in immunosuppressed patients. ${ }^{25,26}$ The large difference for RR in UAT between invasive and in situ SCC may illustrate the higher level of immune dysfunction in invasive SCC probably presenting with chronic inflammation. ${ }^{13}$ Cervical cancer is another HPV related cancer but it showed no increase in RR; the likely reason is its generally earlier onset compared to SCC. Finally, the intriguingly high RR for male breast cancer after invasive SCC could be, if not a fortuitous finding, due to UV-induced chronic inflammation affecting male breast ductal system which is in intimate contact with skin, different from the female breast anatomy.

The study has major strengths in being able to use nationwide and histologically confirmed data on skin tumors, which are not recorded by most cancer registries. SPCs are still rare and for some types of SPCs statistical power was not high. For any benign conditions such as SCC, particularly in situ SCC, an undefined proportion of cases may not be reported to the Cancer Registry; however, the present results were not sensitive to underreporting of FPCs. Nevertheless, reporting of SPC would be critical to this study. Importantly, the present results tended to reassuringly indicate that the reporting rate is at the same level as that for FPCs.

In summary, we found high Spearman rank correlations between incidences of FPC and SPCs. The results support the notion that overall skin SCC does not greatly interfere with the intrinsic carcinogenic process for other cancers. The main deviations in incidence between FPC and SPC appeared to be due to shared risk factors or immunological processes promoting immune responsive cancer types.

\section{Acknowledgments}

We thank Patrick Reilly for excellent language editing. This study was supported by the European Union's Horizon 2020 research and innovation programme, grant No 856620, Jane and Aatos Erkko Foundation, HUCH Research Funds (EVO), Sigrid Juselius Foundation, Finnish Cancer Organizations, University of Helsinki, The Finnish Society of Sciences and Letters, and from the Swedish Research Council (2016-01176 and 2018-02400).

\section{Author Contributions}

All authors made substantial contributions to conception and design, acquisition of data, or analysis and interpretation of data; took part in drafting the article or revising it critically for important intellectual content; gave final approval of the version to be published; and agree to be accountable for all aspects of the work.

\section{Disclosure}

A.H. is a shareholder in Targovax ASA and an employee and shareholder in TILT Biotherapeutics Ltd. The other authors declared no conflict of interest.

\section{References}

1. Vogt A, Schmid S, Heinimann K, et al. Multiple primary tumours: challenges and approaches, a review. ESMO Open. 2017;2(2): e000172. doi:10.1136/esmoopen-2017-000172

2. Travis LB, Demark Wahnefried W, Allan JM, Wood ME, Ng AK. Aetiology, genetics and prevention of secondary neoplasms in adult cancer survivors. Nat Rev Clin Oncol. 2013;10(5):289-301. doi:10. 1038/nrclinonc.2013.41

3. Travis LB, Rabkin CS, Brown LM, et al. Cancer survivorshipgenetic susceptibility and second primary cancers: research strategies and recommendations. J Natl Cancer Inst. 2006;98:15-25. doi:10.10 93/jnci/djj001

4. Chattopadhyay S, Zheng G, Hemminki O, Forsti A, Sundquist K, Hemminki K. Prostate cancer survivors: risk and mortality in second primary cancers. Cancer Med. 2018;7(11):5752-5759. doi:10.1002/ cam4.1764

5. Chattopadhyay S, Hemminki A, Försti A, Sundquist K, Sundquist J, Hemmiinki K. Familial risks and mortality in second primary cancers in melanoma. JNCI Cancer Spectr. 2019;2:pky068. doi:10.1093/ jncics/pky068

6. Chattopadhyay S, Hemminki O, Forsti A, Sundquist K, Sundquist J, Hemminki K. Impact of family history of cancer on risk and mortality of second cancers in patients with prostate cancer. Prostate Cancer Prostatic Dis. 2018.

7. Centre for Epidemiology. Cancer Incidence in Sweden 2012. Stockholm: The National Board of Health and Welfare; 2013.

8. Green AC, Olsen CM. Cutaneous squamous cell carcinoma: an epidemiological review. Br J Dermatol. 2017;177(2):373-381. doi:10.1111/bjd.15324

9. IARC. Personal Habits and Indoor Combustions, Vol. 100E. Lyon: International Agency for Research on Cancer; 2012:575.

10. Omland SH, Ahlstrom MG, Gerstoft J, et al. Risk of skin cancer in patients with HIV: a Danish nationwide cohort study. J Am Acad Dermatol. 2018;79(4):689-695. doi:10.1016/j.jaad.2018.03.024

11. Hortlund M, Arroyo Muhr LS, Storm H, Engholm G, Dillner J, Bzhalava D. Cancer risks after solid organ transplantation and after long-term dialysis. Int J Cancer. 2017;140(5):1091-1101. doi:10.10 02/ijc. 30531 
12. Harwood CA, Toland AE, Proby CM, et al. The pathogenesis of cutaneous squamous cell carcinoma in organ transplant recipients. Br J Dermatol. 2017;177(5):1217-1224. doi:10.1111/bjd.15956

13. Bottomley MJ, Thomson J, Harwood C, Leigh I. The role of the immune system in cutaneous squamous cell carcinoma. Int J Mol Sci. 2019;20(8):2009. doi:10.3390/ijms20082009

14. Ji J, Sundquist K, Sundquist J, Hemminki K. Comparability of cancer identification among death registry, cancer registry and hospital discharge registry. Int J Cancer. 2012;131:2085-2093. doi:10.1002/ijc.27462

15. Pukkala E, Engholm G, Hojsgaard Schmidt LK, et al. Nordic cancer registries - an overview of their procedures and data comparability. Acta Oncol. 2018;57:440-455. doi:10.1080/0284186X.2017.1407039

16. Chen T, Fallah M, Brenner H, et al. Risk of second primary cancers in multiple myeloma survivors in german and swedish cancer registries. Sci Rep. 2016;6:22084. doi:10.1038/srep22084

17. Chen T, Fallah M, Jansen L, et al. Distribution and risk of the second discordant primary cancers combined after a specific first primary cancer in German and Swedish cancer registries. Cancer Lett. 2015;369(1):152-166. doi:10.1016/j.canlet.2015.08.014

18. Chattopadhyay S, Hemminki A, Forsti A, Sundquist K, Sundquist J, Hemminki K. Second primary cancers in patients with invasive and in situ squamous cell skin carcinoma, Kaposi sarcoma and Merkel cell carcinoma: role for immune mechanisms? J Invest Dermatol. 2019.

19. Chattopadhyay S, Sud A, Zheng G, et al. Second primary cancers in non-Hodgkin lymphoma: bi-directional analyses suggesting role for immune dysfunction. Int J Cancer. 2018;143:2449-2457. doi:10.1002/ ijc. 31801
20. Hemminki K, Hemminki O, Försti A, Sundquist K, Sundquist J, Li X. Surveillance bias in cancer risk after unrelated medical conditions: example urolithiasis. Sci Rep. 2017;7:8073. doi:10.1038/ s41598-017-08839-5

21. Emens LA, Ascierto PA, Darcy PK, et al. Cancer immunotherapy: opportunities and challenges in the rapidly evolving clinical landscape. Eur J Cancer. 2017;81:116-129. doi:10.1016/j.ejca.2017. 01.035

22. Rama I, Grinyo JM. Malignancy after renal transplantation: the role of immunosuppression. Nat Rev Nephrol. 2010;6(9):511-519. doi:10.1038/nrneph.2010.102

23. Harms PW, Harms KL, Moore PS, et al. The biology and treatment of Merkel cell carcinoma: current understanding and research priorities. Nat Rev Clin Oncol. 2018;15(12):763-776. doi:10.1038/s41571-0180103-2

24. Rangwala S, Tsai KY. Roles of the immune system in skin cancer. $\mathrm{Br}$ J Dermatol. 2011;165(5):953-965. doi:10.1111/j.1365-2133.2011. 10507.x

25. Zur Hausen $H$. The search for infectious causes of human cancers: where and why. Virology. 2009;392:1-10. doi:10.1016/j.virol.20 09.06.001

26. IARC. Biological agents. Volume 100 B. A review of human carcinogens. IARC Monogr Eval Carcinog Risks Hum. 2012;100(Pt B): $1-441$.
Clinical Epidemiology

\section{Publish your work in this journal}

Clinical Epidemiology is an international, peer-reviewed, open access, online journal focusing on disease and drug epidemiology, identification of risk factors and screening procedures to develop optimal preventative initiatives and programs. Specific topics include: diagnosis, prognosis, treatment, screening, prevention, risk factor modification, systematic reviews, risk \& safety of medical interventions, epidemiology \& biostatistical methods, and evaluation of guidelines, translational medicine, health policies \& economic evaluations. The manuscript management system is completely online and includes a very quick and fair peer-review system, which is all easy to use.

\section{Dovepress}

